\title{
Functions of TAM RTKs in regulating spermatogenesis and male fertility in mice
}

\author{
Yongmei Chen, Huizhen Wang, Nan Qi, Hui Wu, Weipeng Xiong, Jing Ma, Qingxian Lu ${ }^{1}$ \\ and Daishu Han
}

Department of Cell Biology, School of Basic Medicine, Peking Union Medical College, Institute of Basic Medical Sciences, Chinese Academy of Medical Sciences, 5 Dong Dan San Tiao, Beijing 100005, People's Republic of China and ${ }^{1}$ Department of Ophthalmology and Visual Sciences, School of Medicine, University of Louisville, Louisville, Kentucky 40202, USA

Correspondence should be addressed to D Han; Email: dshan@ibms.pumc.edu.cn

\begin{abstract}
Mice lacking TYRO3, AXL and MER (TAM) receptor tyrosine kinases (RTKs) are male sterile. The mechanism of TAM RTKs in regulating male fertility remains unknown. In this study, we analyzed in more detail the testicular phenotype of TAM triple mutant (TAM ${ }^{-/-}$) mice $^{-}$ with an effort to understand the mechanism. We demonstrate that the three TAM RTKs cooperatively regulate male fertility, and MER appears to be more important than AXL and TYRO3. TAM ${ }^{-/-}$testes showed a progressive loss of germ cells from elongated spermatids to spermatogonia. Young adult $\mathrm{TAM}^{-/-}$mice exhibited oligo-astheno-teratozoospermia and various morphological malformations of sperm cells. As the mice aged, the germ cells were eventually depleted from the seminiferous tubules. Furthermore, we found that $\mathrm{TAM}^{-/-}$Sertoli cells have an impaired phagocytic activity and a large number of differentially expressed genes compared to wild-type controls. By contrast, the function of Leydig cells was not apparently affected by the mutation of TAM RTKs. Therefore, we conclude that the suboptimal function of Sertoli cells leads to the impaired spermatogenesis in $\mathrm{TAM}^{-/-}$mice. The results provide novel insight into the mechanism of TAM RTKs in regulating male fertility.

Reproduction (2009) 138 655-666
\end{abstract}

\section{Introduction}

Many male infertility cases are diagnosed as idiopathic. The molecular mechanisms underlying these defects largely remain to be elucidated. By gene targeting technology, male infertility has been demonstrated as a phenotype of the deficiency in various single genes (Matzuk \& Lamb 2002). These genes encode different classes of proteins including cytoskeletal proteins, transcription factors, signal transduction molecules, metabolic enzymes, and membrane proteins. Here, we investigate the role of TAM receptor tyrosine kinases (RTKs) in regulating male fertility.

RTKs, a superfamily of cell surface receptors with a common highly conserved intracellular tyrosine kinase domain (Robinson et al. 2000), are responsible for transmembrane signal transduction after binding of the extracellular domains to their ligands. They are critical for regulation of survival, proliferation and differentiation. Twenty subfamilies of RTKs have been categorized so far based on their amino acid sequence identities and extracellular structural similarities. The members of a subfamily bind common or similar ligands (Manning et al. 2002). The TAM RTK subfamily was identified most recently and contains three members - TYRO3, AXL, and MER (Hafizi \& Dahlback 2006b). Two highly homologous vitamin K-dependent proteins, product of growth arrest-specific gene 6 (Gas6) and protein S (a negative regulator of blood coagulation) are the common ligands of TAM RTKs (Hafizi \& Dahlback 2006a). Studies using gene knockout models have provided direct insights into the physiological functions of TAM RTKs (Lemke \& Rothlin 2008). Mice lacking any single receptor or any combination of two members were viable and capable of producing apparently healthy offspring. However, the TAM triple mutant mice displayed multiple major defects, including broad spectrum autoimmune diseases (Lu \& Lemke 2001, Lemke \& Lu 2003), impaired natural killer cell differentiation (Caraux et al. 2006), hematopoietic abnormalities (Wang et al. 2007, Tang et al. 2009) and male infertility (Lu et al. 1999), suggesting that the three members of TAM RTK subfamily function redundantly or cooperatively.

Attention deserves to be paid to the role of TAM RTKs in regulating male fertility. Mammalian spermatogenesis is characterized by continuous germ cell maturation through various stages including mitotic 
proliferation of spermatogonia, meiotic division of spermatocytes, and morphogenesis of spermatids (spermiogenesis). During this process, more than $75 \%$ of developing spermatogenic cells undergo apoptosis before they mature into spermatozoa in physiological conditions (Dunkel et al. 1997). In the last stage of spermatogenesis, the cytoplasmic portions of elongated spermatids are shed to form residual bodies before extrusion of differentiated sperm into the lumen of seminiferous tubules (Kerr \& de Kretser 1974). The phagocytic clearance of the apoptotic germ cells and residual bodies by Sertoli cells is critical to keeping integrity of the seminiferous epithelium and healthy spermatogenesis (Maeda et al. 2002). The molecular mechanisms of Sertoli cell phagocytosis have not been extensively studied. In the present study, we analyzed the functions of TAM RTKs in regulating spermatogenesis using mice mutant for a series of TAM RTKs. We describe previously unrecognized testicular phenotypes in TAM ${ }^{-1-}$ mice, which may provide novel insights into the mechanism underlying the impaired spermatogenesis due to the mutation of TAM RTKs.

\section{Results}

\section{Expression of TAM RTKs in testicular cells}

To examine the distribution of TAM RTKs in testis, immunohistochemistry on testicular sections was carried out using antibodies against the three proteins. As shown in Fig. $1 \mathrm{~A}$ and $\mathrm{B}$, TYRO3 and $\mathrm{AXL}$ were localized to Sertoli cells; MER was detected both in interstial Leydig cells (LCs) and Sertoli cells (upper panel). In order to confirm the cell-specific expression of TAM RTKs, we performed immunocytochemistry on the isolated primary testicular cells. AXL and TYRO3 proteins were exclusively expressed by Sertoli cells, whereas MER was evidently expressed by both LCs and Sertoli cells. Notably, no signal for TAM RTKs was detected in spermatogenic cells. Consistently, the three TAM RTKs were detected in Sertoli cells by western blotting, MER was also observed in LCs, and none of them were found in germ cells (Fig. 1B). To verify the purity of the testicular cell types, the three cell fractions were characterized by cell type specific markers (Wilm's tumor nuclear protein 1 (WT1) for Sertoli cells, VASA for germ cells, 3 $\beta$-hydroxysteroid dehydrogenase 1 (HSD3B1) for LCs). As shown in Fig. 1C, each cell fraction specifically expressed the cell type marker, indicating that the cell fractions were not contaminated by other cell types. Notably, TAM RTKs were absent in Sertoli cells isolated from TAM $^{-1-}$ mice (data not shown), confirming that TAM RTKs alleles are null in the triple mutant mice.

\section{Fertility of TAM RTKs mutant mice}

To dissect the role of each TAM RTK on male fertility, TAM RTK single, double and triple mutant mice were examined on their fertility, testis development and sperm count. The results are listed in Table 1 . No significant difference in the body weight of mice carrying different genotypes was observed. However, significant decreases in the testis weight, sperm production and fertility were found in mice with some genotypes. As expected, the most severe phenotype was observed in the triple knockouts. TAM ${ }^{-1-}$ mice never sired offspring. The weight of testis in $\mathrm{TAM}^{-1-}$ mice was one third that in WT controls at 15 weeks of age. Very few sperm were found in $\mathrm{TAM}^{-1-}$ epididymis. Although all other genotype mice were fertile, the mice doubly mutant for Axl/Mer $\left(\mathrm{AM}^{-1-}\right)$ and Tyro3/Mer $\left(\mathrm{TM}^{-1-}\right)$ exhibited significant decreases in testis weight, sperm count, and

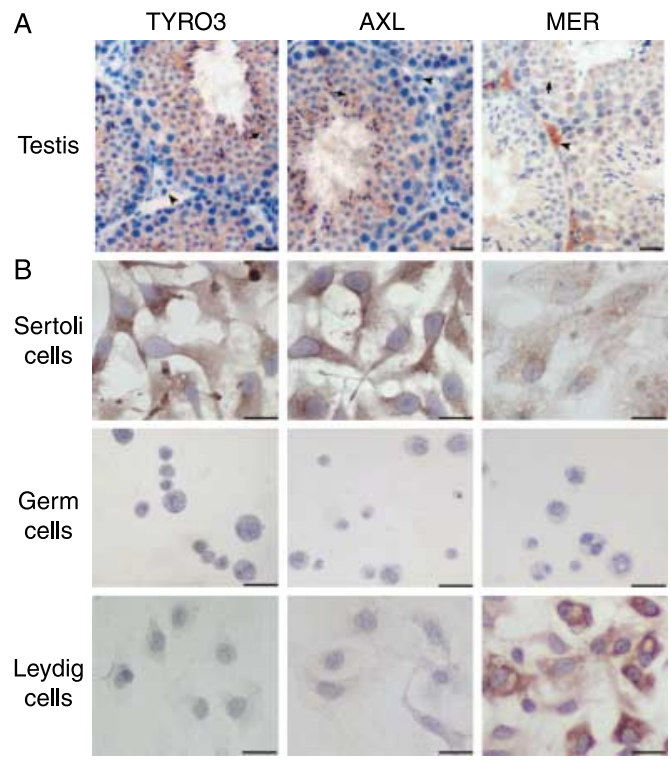

Reproduction (2009) 138 655-666

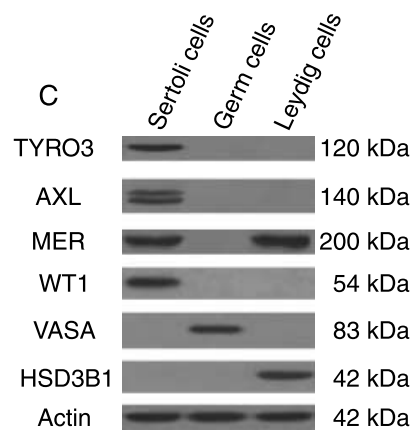

Figure 1 Expression of TAM RTKs in testicular cells. (A) Immunohistochemistry for TAM RTKs in testis. (B) Immunocytochemistry for the proteins of TYRO3, AXL, and MER on primary Sertoli cells, germ cells, and Leydig cells. Scale bar $=$ $10 \mu \mathrm{m}$. (C) Western blotting analysis for TYRO3, AXL, MER, and cell type-specific markers (WT1 for Sertoli cells, VASA for germ cells and HSD3B1 for Leydig cells) in the three types of testicular cells. $\beta$-actin was used to monitor the loading samples. TYRO3 and AXL were exclusively expressed in Sertoli cells, but MER was expressed in both Sertoli cells and Leydig cells. No signal for TAM RTKs was detected in germ cells. The cell type-specific marker proteins were detected in the corresponding cell populations. 
Table 1 Male fertility-related phenotypes of mice with different genotypes.

\begin{tabular}{|c|c|c|c|c|}
\hline Genotypes of male mice & Body weight $(\mathrm{g})^{\mathrm{a}}$ & Testis weight $(\mathrm{mg})^{\mathrm{a}}$ & $\begin{array}{l}\text { Number of sperm } \\
\left(\times 10^{7} / \text { epididymis }\right)^{a}\end{array}$ & Fertility (offsprings/cage) ${ }^{b}$ \\
\hline$A^{-1-}$ & $27.65 \pm 2.27$ & $112.23 \pm 4.34$ & $2.34 \pm 0.22$ & $58 \pm 5$ \\
\hline $\mathrm{T}^{-1-}$ & $26.98 \pm 3.11$ & $106.00 \pm 4.17$ & $2.16 \pm 0.31$ & $57 \pm 4$ \\
\hline $\mathrm{M}^{-1-}$ & $27.43 \pm 2.30$ & $109.08 \pm 3.78$ & $2.60 \pm 0.14$ & $56 \pm 5$ \\
\hline $\mathrm{AT}^{-1-}$ & $25.27 \pm 3.14$ & $100.00 \pm 5.13$ & $2.55 \pm 0.24$ & $54 \pm 3$ \\
\hline $\mathrm{AM}^{-1-}$ & $27.52 \pm 2.58$ & $80.00 \pm 4.67^{*}$ & $1.65 \pm 0.17^{*}$ & $41 \pm 5^{*}$ \\
\hline $\mathrm{TM}^{-1-}$ & $25.36+2.73$ & $74.50+4.14 *$ & $1.52+0.37 *$ & $38+3 *$ \\
\hline $\mathrm{TAM}^{-1-}$ & $25.00 \pm 3.03$ & $35.00 \pm 4.76^{\dagger}$ & $0.31 \pm 0.09^{\dagger}$ & $0 \pm 0^{\dagger}$ \\
\hline WT & $27.38 \pm 2.65$ & $115.17 \pm 4.43$ & $2.71 \pm 0.14$ & $56 \pm 3$ \\
\hline
\end{tabular}

${ }^{*} P<0.05 ;{ }^{\dagger} P<0.01$.

${ }^{\mathrm{a}}$ Data are presented as means \pm s.E.M. of 10 -week-old mice $(n=10) .{ }^{\mathrm{b}}$ Fertility is presented as means \pm S.E.M. of 3 cages during mating of TAM ${ }^{-1-}$ male and WT female for 6 months. $\mathrm{A}^{-1-}, \mathrm{T}^{-/-}$, and $\mathrm{M}^{-1-}$ represent Tyro3, Axl, and Mer single mutants respectively, $\mathrm{AM}^{-1-}$ represents $A x I / M e r$ double mutants, and so forth. TAM ${ }^{-/-}$and WT represent Tyro3/Axl/Mer triple mutant and wild-type mice.

fertility compared with WT mice. In contrast, all single mutant mice and Tyro3/Axl double mutants $\left(\mathrm{TA}^{-{ }^{-}}\right.$) exhibited normal fertility. These results indicate that the three TAM RTKs cooperatively regulate spermatogenesis. That all mice with compromised fertility carry the Mer null allele suggests that MER is more important than AXL and TYRO3 in regulating male fertility.

\section{Progressive loss of germ cells during post-natal development of TAM $^{-/-}$testis}

Since TAM RTKs triple knockouts were male sterile, we then further examined the spermatogenesis of $\mathrm{TAM}^{-1-}$ mice (Fig. 2). We found a progressive loss of germ cells as TAM ${ }^{-\prime-}$ mice aged. At week 2 after birth, histological appearance of the testes from both $\mathrm{TAM}^{-1-}$ and WT mice was similar, the seminiferous tubules contain Sertoli cells, spermatogonia and primary spermatocytes in number comparable. On week 3, the most tubules of
$\mathrm{TAM}^{-1-}$ and WT testes showed the presence of round spermatids. However, a delayed progression of germ cell differentiation was occasionally observed in some tubules of $\mathrm{TAM}^{-1-}$ testis, where the most advanced germ cells were late-stage spermatocytes. On week 8, the elongated spermatids were much less in $\mathrm{TAM}^{-1-}$ tubules than WT controls. Frequently, multiple steps of spermatids appeared on a same tubular section, suggesting an unsynchronized spermatogenesis. These observations indicate that the maturation of germ cells in the first wave of spermatogenesis in $\mathrm{TAM}^{-1-}$ mice is delayed when spermatocytes proceed to spermatids. The impaired spermatogenesis became more severe as mice aged. At week 15, multinucleate giant cells containing multiple nuclei within a single cytoplasm were frequently observed in $\mathrm{TAM}^{-1-}$ seminiferous tubules, indicating a defect on the breaking up cytoplasmic bridges between sister spermatids. Although all stages of germ cells were present in most $\mathrm{TAM}^{-/-}$tubules
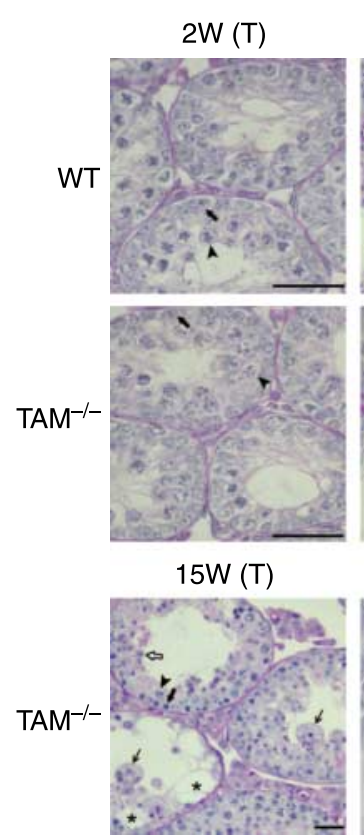

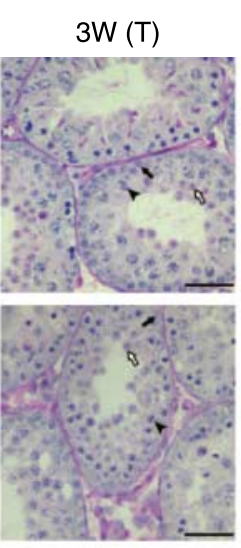

$30 \mathrm{~W}(\mathrm{~T})$

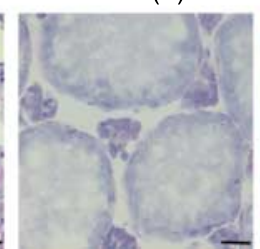

$8 \mathrm{~W}(\mathrm{~T})$

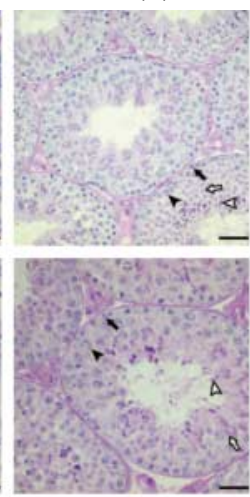

$15 \mathrm{~W}(\mathrm{E})$



$8 \mathrm{~W}(\mathrm{E})$

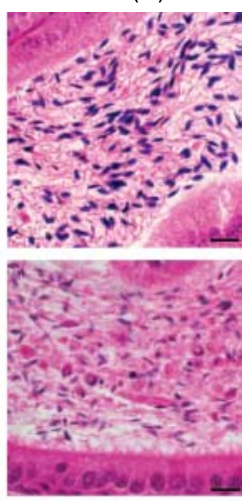

$30 \mathrm{~W}(\mathrm{E})$

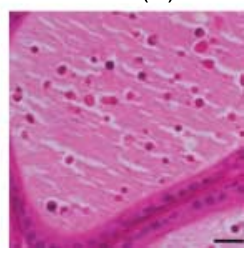

Figure 2 Histological analysis on the progressive loss of germ cells in $\mathrm{TAM}^{-1-}$ mice during postnatal development. Testes (T) and epididymides (E) of mice at different ages were examined by PAS staining and HE staining respectively. The loss of germ cells first occurred in spermatids at the first wave of spermatogenesis at 3 weeks of age (3W), and became more severe as mice aged. The germ cells were depleted at 30 weeks of age. A few spermatozoa and numbers of degenerated round cells presented in epididymides of young adult $\mathrm{TAM}^{-1-}$ mice at 8 and 15 weeks of ages, and the epididymal tubules contained only sparse degenerated round cells at 30 weeks of age. Histological structures of wild-type (WT) testes and epididymides of 8-week-old mice were presented as the representatives. Closed arrows, closed arrowheads, open arrows and open arrowheads indicate spermatogonia, spermatocytes, round spermatids, and elongated spermatids respectively. Arrows and asterisks indicate multinucleate giant cells and vacuoles. Scale bar $=20 \mu \mathrm{m}$. 
at 15 weeks of age, many fewer spermatids and spermatocytes were observed compared to WT controls. Meanwhile, the vacuoles were frequently seen in the seminiferous epithelium. Further loss of the early stage of germ cells occurred thereafter. Up to 30 weeks of age, almost all the seminiferous tubules were completely devoid of germ cells in TAM ${ }^{-/-}$testes. Consistent with these observations, the epididymides of $\mathrm{TAM}^{-1-}$ mice were filled with sparse spermatozoa and abundant degenerated round cells at 8 and 15 weeks of age (Fig. 2). At 30 weeks of age, the $\mathrm{TAM}^{-1-}$ epididymides contained only sparse degenerated round cells. In controls, the epididymides of adult WT mice were filled with plenty of spermatozoa, and very few round cells were observed. Taken together, the observations demonstrate that the germ cells were progressively lost from spermatids to spermatocytes, and finally spermatogonia as $\mathrm{TAM}^{-1-}$ mice aged.

\section{Apoptosis and proliferation of germ cells}

To clarify whether the germ cell loss is due to cell apoptosis or defective proliferation, we analyzed cell apoptosis and proliferation based on TUNEL assay and immunostaining for proliferating cell nuclear antigen (PCNA). We found massive apoptotic spermatids in the testis of 10-week-old TAM $^{-1-}$ mice (Fig. 3A). As mice aged, more apoptotic early stage of germ cells appeared. Apoptotic germ cells were rarely observed in adult WT mice. On the other hand, we did not find evident impaired proliferation of spermatogonia in adult $\mathrm{TAM}^{-1-}$ mice (Fig. 3B). The results suggest that the loss of germ cells in $\mathrm{TAM}^{-1-}$ testis mainly results from the increased cell apoptosis, not absence of spermatogonia proliferation. Consistent with the loss of germ cells, the seminiferous tubule diameter was significantly decreased in $\mathrm{TAM}^{-/-}$mice at 15 weeks of age and older (Fig. 3C). The decreased tubule diameter should reflect a total germ cell complement.

\section{Oligo-astheno-teratozoospermia in young adult $\mathrm{TAM}^{-1-}$ mice}

Although $\mathrm{TAM}^{-1-}$ males never sired offspring, spermatozoa appeared in the testes and epididymides of young adult mice. However, the number of epididymal spermatozoa in 10 -week-old $\mathrm{TAM}^{-/-}$mice is $12 \%$ of that in WT controls (Fig. 4A). Moreover, only $15 \%$ of $\mathrm{TAM}^{-1-}$ spermatozoa were motile (Fig. $4 \mathrm{~B}$ ), and the motile spermatozoa beat less vigorously and generated less forward momentum. Notably, most of the spermatozoa exhibited morphological malformation. The more prevalent shapes were depicted in Fig. 4C: with a head being curled back onto the midpiece (a), with a coiled of tail (b), having two heads (c and d), and multiple spermatozoa bundled by unidentified material (e and f); $<10 \%$ of spermatozoa showed normal morphological features (g). Male infertility of $\mathrm{TAM}^{-1-}$ mice could be attributable to oligo-astheno-teratozoospermia. The malformation of spermatozoa was further revealed by electron microscopic examination (Fig. 4D). Compared to controls ( $\mathrm{a}$ and $\mathrm{b}$ ), the most epididymal spermatozoa of $\mathrm{TAM}^{-1-}$ mice showed a deformity of head shape characterized by their irregular acrosomes, which were expanded or partially detached from the nucleus membrane (c and d). Notably, most mitochondria failed to arrange helicoidally around the axoneme in the middle piece of spermatozoa (e and f). The mitochondria were completely absent in some sperm (g). The deformation of mitochondrial sheaths might be responsible for the defective motility of $\mathrm{TAM}^{-/-}$spermatozoa.
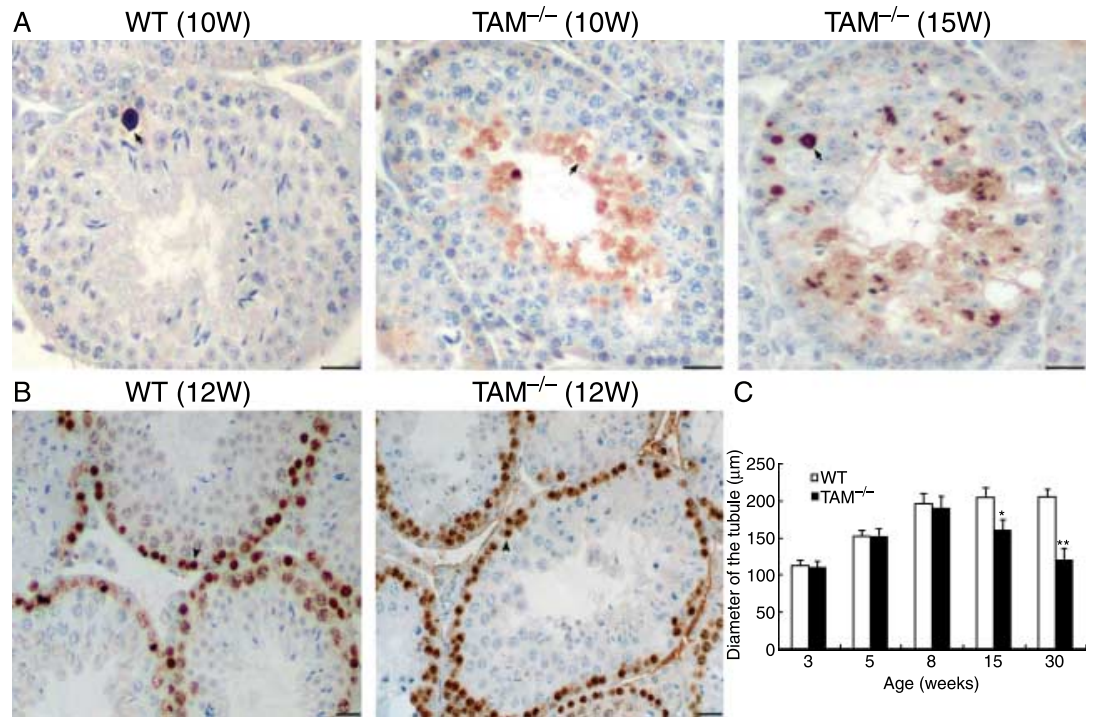

Figure 3 Apoptosis and proliferation of germ cells in WT and $\mathrm{TAM}^{-1-}$ testes. (A) TUNEL staining for apoptotic germ cells on the testes of 10 and 15 weeks (10W and $15 \mathrm{~W})$ old mice, showing increased apoptotic germ cells in $\mathrm{TAM}^{-1-}$ testes. Arrows indicate apoptotic cells. (B) PCNA staining for the detection of cell proliferation on the testes of 12 weeks $(12 \mathrm{~W})$ old mice, showing comparable proliferation of spermatogonia in WT and $\mathrm{TAM}^{-1-}$ testes. Arrowheads indicate proliferating cells. (C) Diameter of seminiferous tubules at different ages of mice was assessed under a light microscope. The data were represented as mean \pm S.E.M. of 150 tubules in three animals. ${ }^{*} P<0.05,{ }^{* *} P<0.01$. Scale bar $=20 \mu \mathrm{m}$. 


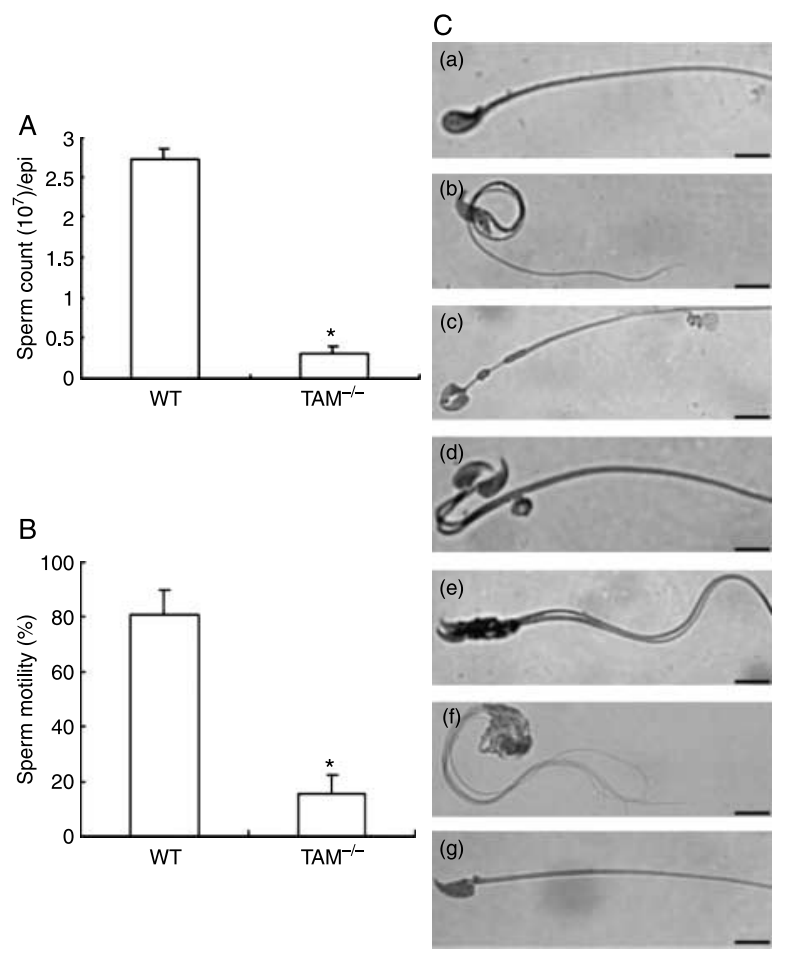

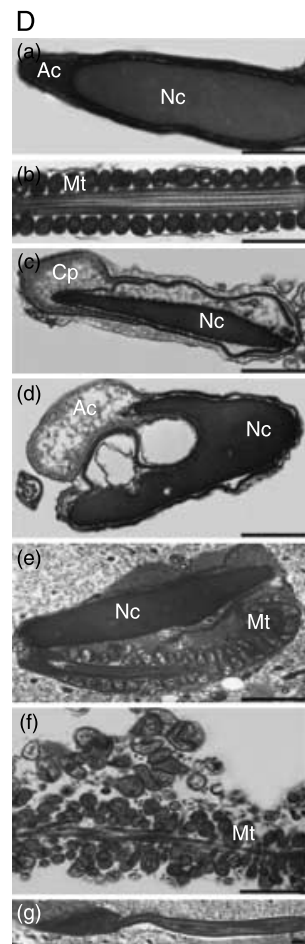

Figure 4 Oligo-astheno-teratozoospermia in $\mathrm{TAM}^{-1-}$ mice. (A) Sperm number each epididymis (data were from Table 1). (B) Sperm motility. The data were represented as mean \pm s.E.M. of 10 mice at 10 weeks of age, ${ }^{*} P<0.05$. (C) The representatives of morphological abnormalities of $\mathrm{TAM}^{-1-}$ spermatozoa from the caudal epididymides under light microscope with magnification of $\times 1000$. (a) Sperm with a head curled back onto the midpiece; (b) sperm with a coiling tail; (c and d) sperm with two heads; (e and f) multiple spermatozoa bundled together, (g) sperm with normal morphological features. Scale bar $=5 \mu \mathrm{m}$. (D) Electron microscopic analysis on sperm heads and mitochondria. (a) Normal sperm head of wild-type mice showed regular acrosome (Ac) and nucleus $(\mathrm{Nc})$; (b) normal mitochondria sheath (Mt) of wild-type sperm; (c) expanded acrosome and cytoplasm (Cp) of $\mathrm{TAM}^{-1-}$ sperm; (d) degenerated acrosome and abnormal shaped nucleus; (e and $f$ ) defects of mitochondria sheaths; (g) sperm lacking mitochondria. Scale bar $=1 \mu \mathrm{m}$.

\section{Impaired phagocytic ability of TAM ${ }^{-/-}$Sertoli cells}

Given that all TAM RTKs were expressed in Sertoli cells, not germ cells, it was reasonable to speculate that they primarily act on Sertoli cells and thus regulate spermatogenesis. Therefore, the characteristics of Sertoli cells were examined in $\mathrm{TAM}^{-1-}$ mice. Based on immunostaining for WT1 (a nuclear marker of Sertoli cells) (Fig. 5A), the number of Sertoli cells was comparable (17.1 \pm 0.22 vs $16.4 \pm 0.18 /$ tubular section) in $\mathrm{TAM}^{-1-}$ and WT seminiferous tubules at 8 weeks of age. At 30 weeks of age, although most of the seminiferous tubules in $\mathrm{TAM}^{-1-}$ testis contain only Sertoli cells, the number of Sertoli cells was still consistent within $\mathrm{TAM}^{-1-}$ and WT tubules (17.6 \pm 0.23 vs $17.9 \pm 0.29$ /tubular section). The results indicate that the mutation of TAM RTKs does not affect survival of Sertoli cells. In order to assess the maturation state of $\mathrm{TAM}^{-1-}$ Sertoli cells, we examined the expression of major differentiation markers in isolated primary Sertoli cells by quantitative RT-PCR. The androgen receptor, androgen binding protein and anti-Müllerian hormone were comparably expressed at the mRNA level in WT and $\mathrm{TAM}^{-1-}$ Sertoli cells (Fig. 5B), suggesting that Sertoli cells can normally mature in the mutants.

One of the Sertoli cell's functions is the phagocytic clearance of apoptotic germ cells and residual bodies, which is necessary for normal spermatogenesis. We recently demonstrated in vitro that GAS6 and TAM RTKs regulate the phagocytosis of apoptotic germ cells by Sertoli cells (Xiong et al. 2008). To examine whether the mutation of TAM RTKs in Sertoli cells impairs their phagocytic function in vivo, we analyzed dynamics of lipid droplet formation in the seminiferous epithelium during testis development postnatal. Lipid droplets can be formed by Sertoli cells after engulfment of apoptotic germ cells and residual bodies, which can be a criterion to evaluate phagocytic ability of Sertoli cells (Wang et al. 2006). By Oil Red O (ORO) staining on testis sections, we found an increased lipid droplet number in basal compartment of the seminiferous epithelium during development of WT testes (Fig. 5C). However, the number of lipid droplets in $\mathrm{TAM}^{-1-}$ seminiferous tubules was significantly lower compared with that in WT controls at 3 weeks of age. In 8-week-old WT mice, the lipid droplets showed stage-dependant variation with a peak number at the stages IX-I (Fig. 5C), where phagocytosis of residual bodies take places. Notably, significantly fewer lipid droplets were observed at the same stage of $\mathrm{TAM}^{-1-}$ tubules, although massive degenerated spermatogenic cells appeared in the tubules. The decreased lipid droplets could reflect an impaired phagocytotic ability of TAM ${ }^{-1-}$ Sertoli cells. This result is agreement with that obtained in our previous in vitro study (Xiong et al. 2008).

\section{Characteristics of LCs in $\mathrm{TAM}^{-/-}$testis}

Since MER was also evidently expressed in interstitial LCs, we asked whether the mutation of TAM RTKs affects the function of LC. Therefore, the characteristics of LCs were compared in WT and $\mathrm{TAM}^{-1-}$ testes. LCs were 


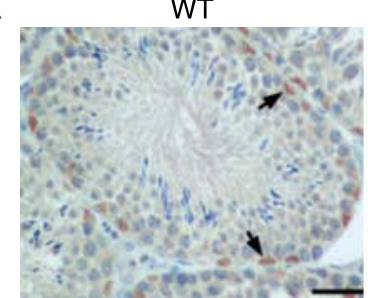

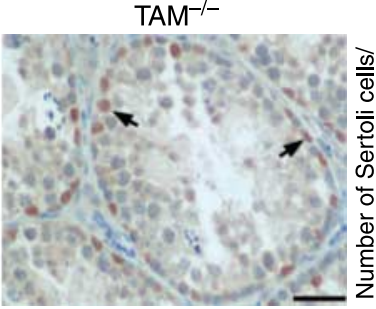

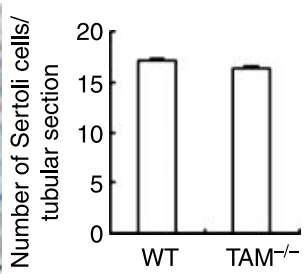

B

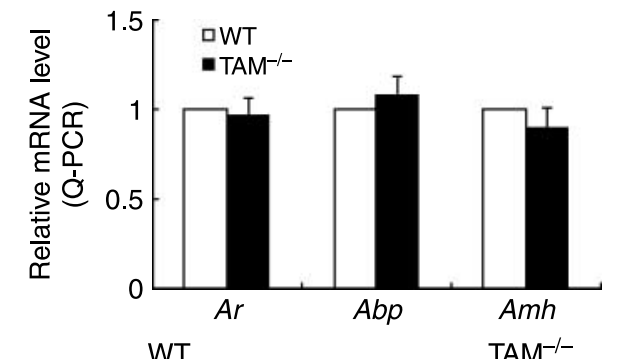

C WT
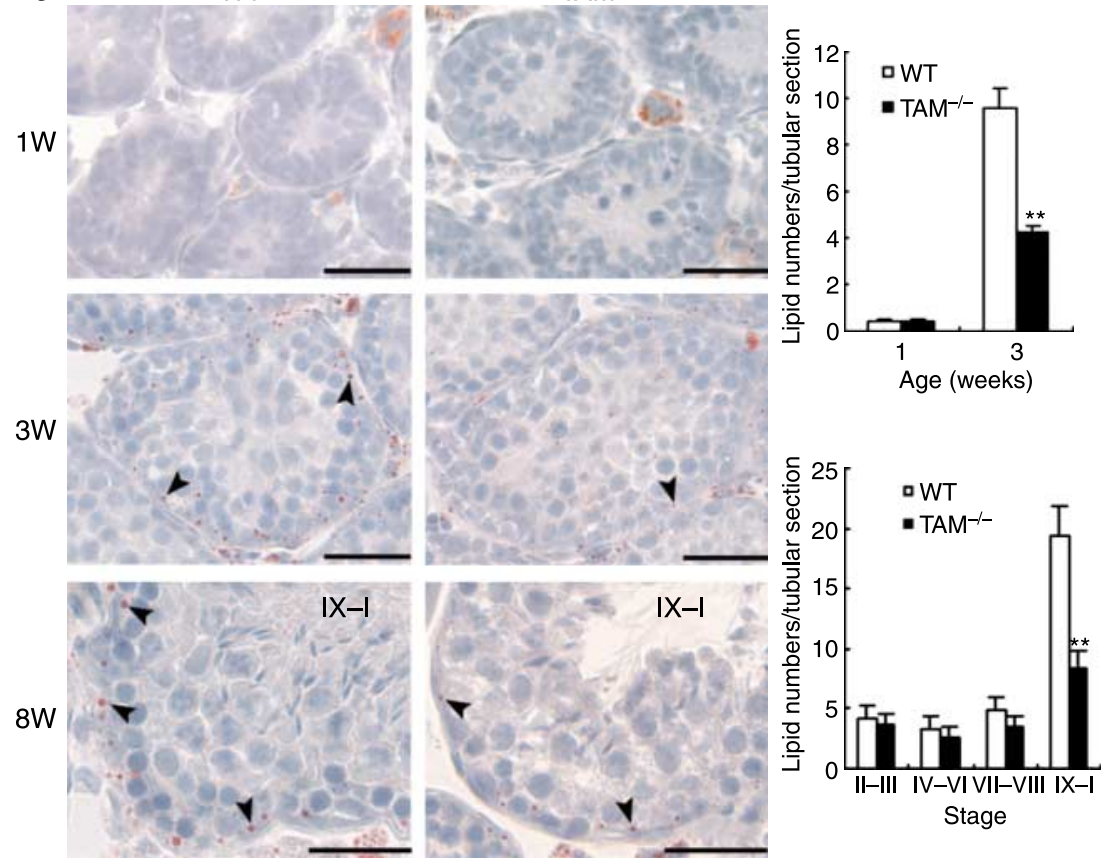

isolated from $\mathrm{TAM}^{-1-}$ and $\mathrm{WT}$ testes, and stained for HSD3B1 (Fig. 6A). By counting HSD3B1-positive cells at different ages of mice, we found a comparable LC number in $\mathrm{TAM}^{-1-}$ and WT testes (Fig. 6B). LC number increased sharply from 3 to 5 weeks of age, and remained consistent thereafter. One important function of LCs is the production of testosterone, which plays a critical role in maintaining spermatogenesis. RIA showed similar serum testosterone levels (Fig. 6C) in 15-week-old $\mathrm{TAM}^{-1-}$ and WT mice. Furthermore, based on the data of microarray analysis, we did not find differential expression of the genes that are specifically expressed in LC and play critical roles in regulating spermatogenesis in WT and $\mathrm{TAM}^{-1-}$ testes (Supplementary Table 1, which can be viewed

Figure 5 Characteristics of Sertoli cells. (A) Immunohistochemical staining for WT1 (a nuclear marker of Sertoli cells) showed a consistent number of Sertoli cells (arrows) in WT and $\mathrm{TAM}^{-1-}$ seminiferous tubules. (B) Realtime PCR analysis for major differentiation marker genes of Sertoli cells. Comparable expression level of the marker genes in WT and mutant Sertoli cells suggests that $\mathrm{TAM}^{-/-}$Sertoli cells can mature normally. (C) Histological analysis of lipid droplets (arrowheads) in Sertoli cells after Oil Red O staining during early testicular development postnatal. The images are representative of testes of 1-week-old (upper panel) and 3-week-old (middle panel) mice. Seminiferous tubule stagedependent variation of the lipid droplet number in adult mice, the images are representative of the stages IX-I of 8-week-old mice (lower panel). Scale bar $=20 \mu \mathrm{m}$. The data were expressed as means \pm s.D. of 60 tubules from three animals. $* * P<0.01$. Scale bar $=20 \mu \mathrm{m}$. online at www.reproduction-online.org/supplemental/), such as $\mathrm{LH}$ receptor and three steroidogenic enzymes (HSD3B1, p450c17 and p450scc). The results suggest that the maturation and functions of LC are not apparently affected by the lack of TAM RTKs.

\section{Gene expression profile of $\mathrm{TAM}^{-/-}$testes}

To further understand the molecular consequences of TAM RTK mutation in testis, we analyzed the gene expression profile of $\mathrm{TAM}^{-1-}$ and WT testes using a mouse microarray (GeneChip Mouse Genome 430/2.0, Affymetrix, Santa Clara, CA, USA) containing a total of 39000 probe sets targeting all known mouse gene transcripts. The testes from 3-week-old mice were used 

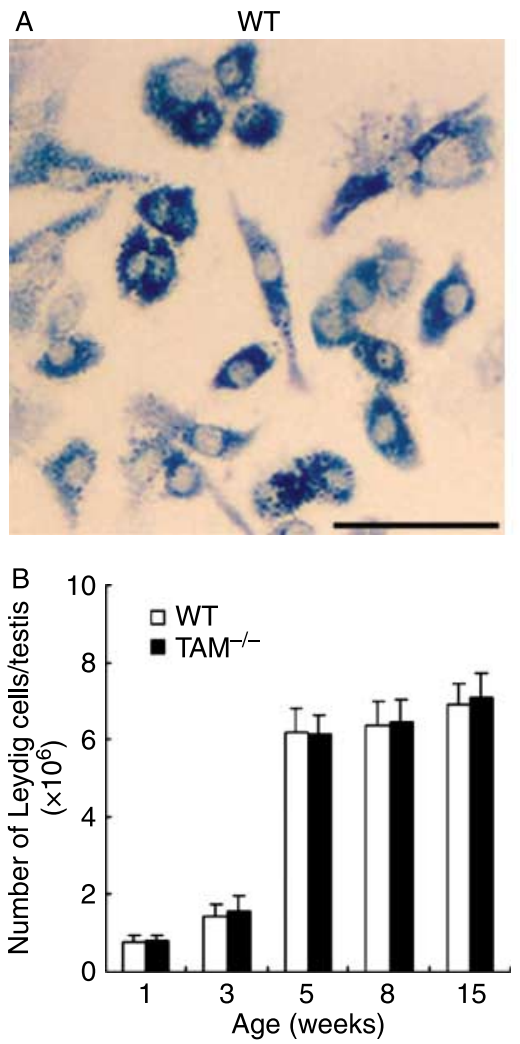

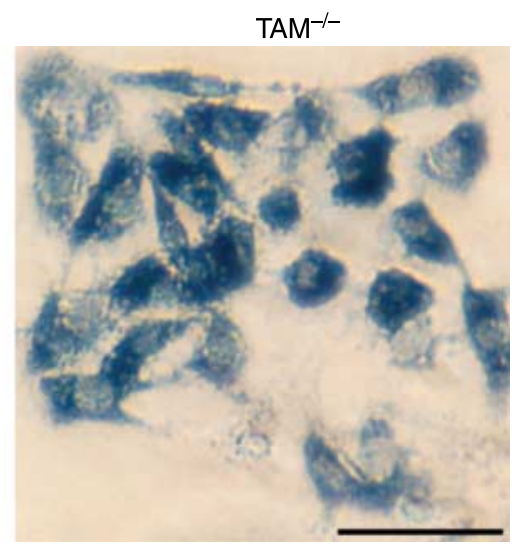

C

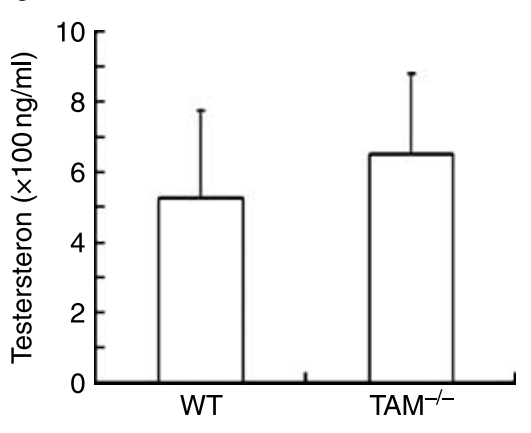

Figure 6 Characteristics of Leydig cells. (A) Cytochemical staining for HSD3B1 on Leydig cells. The images were representatives of the isolated Leydig cells from 8-week-old mice. (B) Leydig cell number per testis at different ages of mice. The data were represented as mean \pm S.E.M. of five mice. (C) Serum testosterone levels of 15-week-old mice. The data were represented as mean \pm S.E.M. of 10 animals. Scale bar $=20 \mu \mathrm{m}$. for the microarray analysis, because there are similar testicular cell fractions in the testes of $\mathrm{TAM}^{-1-}$ and WT mice at this age. The genes that are up- and downregulated by more than twofold in $\mathrm{TAM}^{-1-}$ testes compared to WT controls were 287 and 149 respectively (Supplementary Table 1). Notably, TAM RTKs were listed as the mostly downregulated genes, indicating that the microarrary system works well. Onto-Express was used to classify the differentially expressed genes according to their biological functions (Fig. 7A).

Furthermore, we selected several differentially expressed genes based on their predominant expression in Sertoli cells as well as possible biological significance, and verified their expression in isolated primary Sertoli cells by real-time PCR. We confirmed the differential expression of three upregulated and three downregulated genes in $\mathrm{TAM}^{-1-}$ Sertoli cells (Fig. 7B). Notably, the expression of $\mathrm{N}$-cadherin was significantly reduced in $\mathrm{TAM}^{-1-}$ Sertoli cells. N-cadherin is critical for spermatogenesis by mediating the formation of ectoplasmic specialization (EP) between Sertoli cells and spermatids. The down-regulation of $\mathrm{N}$-cadherin in $\mathrm{TAM}^{-1-}$ Sertoli cells might perturb EP formation and thus impaired spermatid maturation. The expression of Cd36, a scavenger receptor in Sertoli cells to mediate the phagocytosis of apoptotic spermatogenic cells, was also significantly downregulated in $\mathrm{TAM}^{-/-}$Sertoli cells, which might contribute to the impaired phagocytic ability of TAM ${ }^{-1-}$ Sertoli cells. Among the upregulated genes, tumor necrosis factor- $\alpha(\operatorname{Tnf})$ was upregulated by 12 -fold in $\mathrm{TAM}^{-1-}$ Sertoli cells. The roles of TNF in regulating survival and death of germ cells were controversial. The marked up-regulation of Tnf in $\mathrm{TAM}^{-1-}$ Sertoli cells could involve in the impaired spermatogenesis. The expression of lactate dehydrogenase $C(L d h c)$ was increased by 18 -fold in $\mathrm{TAM}^{-1-}$ Sertoli cells, suggesting a changed metabolism due to TAM RTKs mutation. Although an abrogation of Mer expression in TAM $^{-1-}$ Sertoli cells was expectable, we surprisingly confirmed a significant up-regulation of Gas6 in the mutant Sertoli cells. The gene expression profile of TAM ${ }^{-1-}$ testis could provide clues to understand the molecular mechanisms of TAM RTKs in regulating spermatogenesis.

\section{Discussion}

A previous study demonstrated that TAM RTK triple mutant male mice are sterile (Lu et al. 1999). Here we analyzed in detail the functions of TAM RTKs in regulating male fertility and possible mechanisms underlying the defects due to TAM RTK mutation. The results expand the previous report and provide novel insight into the roles of TAM RTKs in regulating spermatogenesis. 

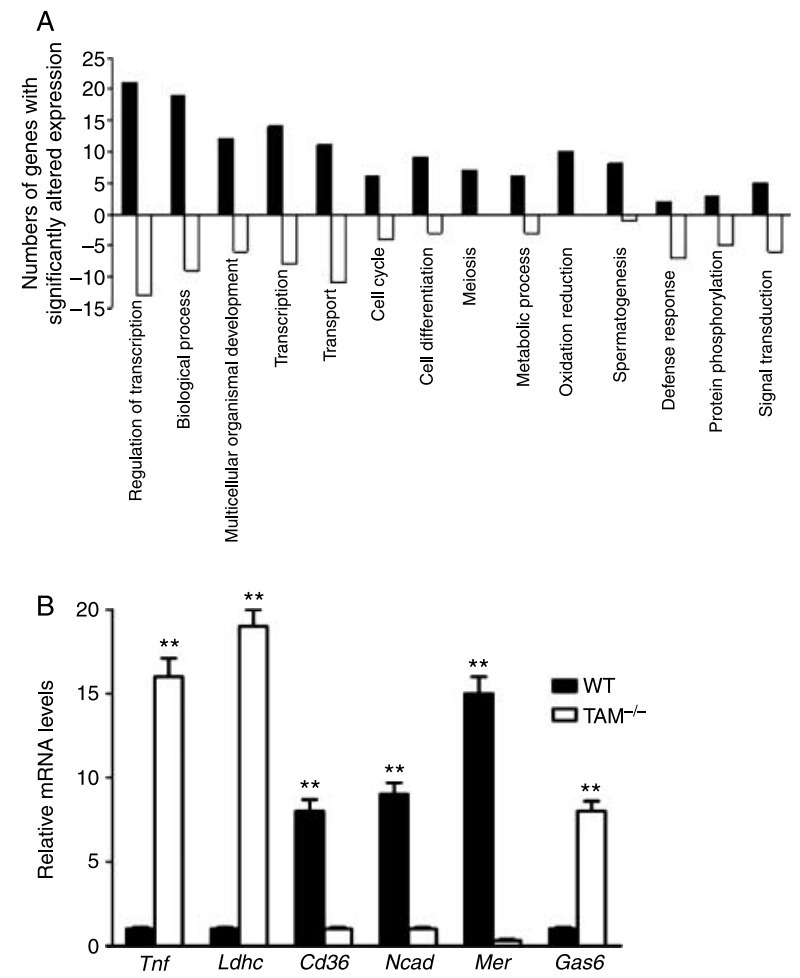

Figure 7 Gene expression analysis. (A) Microarray analysis of testis RNAs from TAM ${ }^{-1-}$ and WT mice. The differentially expressed genes are shown by classification according to their likely biological function based on the data of Supplementary Table 1. (B) Relative mRNA levels detected by real-time PCR in WT and TAM ${ }^{-1-}$ Sertoli cells. The genes were selected based on their marked differential expression in WT and $\mathrm{TAM}^{-1-}$ testes as microarray analysis, and possible biological significance in regulating spermatogenesis. $L d h c$, lactate dehydrogenase C; Ncad, N-cadherin. The data were represented as means \pm s.E.M. of three experiments. ${ }^{* *} P<0.01$.

We found that the three TAM RTKs regulate male fertility in a cooperative manner. Mer knockout is necessary for the impaired fertility in the double mutant mice, suggesting that MER may be more important than TYRO3 and AXL in regulating male fertility. Impaired germ cell maturation in $\mathrm{TAM}^{-1-}$ mice was observed at the first wave of spermatogenesis, and became more severe as the mice aged. In young adult $\mathrm{TAM}^{-1-}$ mice, this defect is characterized by an impaired spermiogenesis. During spermiogenesis, the round spermatids synchronously elongate, condense their nuclei, acquire flagellar and acrosomal structures, and shed a great portion of their cytoplasm (as residual bodies) to form spermatozoa (Cheng \& Mruk 2002). Defects of these events leads to a lack of mature spermatozoa, which is a major cause of male infertility in humans (Ezeh 2000). The round spermatids in the young adult $\mathrm{TAM}^{-1-}$ mice mostly failed to elongate. The presence of multinucleate giant cells suggests a failure in the shedding of residual bodies and the breaking up of intercellular bridges between sister spermatids. Oligo-astheno-teratozoospermia has been observed in the mice mutant for other genes such as Rxrb (Kastner et al. 1996), Cont-7 (Nakamura et al. 2004) and Tslc1 (van der Weyden et al. 2006, Yamada et al. 2006). The young adult $\mathrm{TAM}^{-/-}$mice exhibited severe oligo-astheno-teratozoospermia. Various morphological malformations of sperm were found in $\mathrm{TAM}^{-1-}$ mice. Malformed sperm were observed in some infertile men with teratozoospermia (Baccetti et al. 1979, Lewis-Jones et al. 2003). The observations in this study could provide novel insight into the etiology of oligo-astheno-teratozoospermia. Electron microscopy showed malformed heads and mitochondria sheaths in TAM ${ }^{-1-}$ spermatozoa, which could contribute to the asthenospermia. The sperm mitochondria deformation was reported in Cont7 null mice, and the head abnormalities were also observed in Ts/c1 and nectin-2 null mice (Mueller et al. 2003). Our present study provides a novel example of oligo-astheno-teratozoospermia, which results from the mutation of TAM RTKs.

Impaired spermatogenesis should not be germ cell autonomous in $\mathrm{TAM}^{-1-}$ mice because no one TAM RTK was expressed in the germ cells. In contrast, all three TAM RTKs were co-expressed in Sertoli cells, suggesting that they primarily affect Sertoli cells and thus regulate spermatogenesis. Sertoli cells are critical for normal spermatogenesis. Germ cell survival during the first wave of spermatogenesis is lower than in subsequent waves probably because Sertoli cell function is not optimal unless it is exposed to a full complement of germ cells. The germ cell degeneration and teratozoospermia due to the suboptimal Sertoli cell function have been documented in a number of mouse mutants (Kastner et al. 1996, Russell et al. 2001, Firestein et al. 2002, Nakamura et al. 2004, Ogawa et al. 2004). A recent study demonstrated that dimeric transferrin in Sertoli cells modulates the phagocytosis of residual bodies (Yefimova et al. 2008). We demonstrated in this study that the survival and differentiation of Sertoli cells are not affected by the mutation of TAM RTKs, but their phagocytic function is impaired. Normal phagocytic function of Sertoli cells is necessary for healthy spermatogenic cells to proceed through spermatogenesis (Maeda et al. 2002). One explanation for how the timely removal of apoptotic cells and residual bodies contributes to spermatogenesis is the prevention of leaking out noxious contents and poisoning healthy cells (Nakanishi \& Shiratsuchi 2004). We recently demonstrated that the apoptotic spermatogenic cells and residual bodies can be used to produce energy by Sertoli cells after the phagocytosis of them (Xiong et al. 2009). The net output of energy by Sertoli cells is important not only to spermatogenesis, but also to germ cell movement (Mruk \& Cheng 2004). Impaired Sertoli cell phagocytosis may result in a decrease in the energy production by Sertoli cells. On the other hand, although MER was also evidently expressed in LCs, we did not observe any apparent defect of LC functions that are 
critical for spermatogenesis due to lacking TAM RTKs. Therefore, the defect of Sertoli cell phagocytosis could be a major cause of the impaired spermatogenesis in $\mathrm{TAM}^{-1-}$ mice.

We finally compared the gene expression profiles of $\mathrm{TAM}^{-1-}$ and WT testes. A large number of differentially expressed genes were found in $\mathrm{TAM}^{-1-}$ testes compared to WT controls. The number of upregulated genes was almost two times that of downregulated genes in $\mathrm{TAM}^{-1-}$ testes (287 vs 149), which is agreement with the knowledge that TAM RTKs negatively regulate various transcription factors including nuclear factor $\kappa B$ (NFKB) activation (Lemke \& Rothlin 2008). N-cadherin was one of the most profound downregulated genes in $\mathrm{TAM}^{-1-}$ Sertoli cells. It has been known that $\mathrm{N}$-cadherin mediates Sertoli cell-spermatid adhesion (Newton et al. 1993). The down-regulation of $\mathrm{N}$-cadherin might perturb the adhesion between Sertoli cells and spermatids, thus result in a primary damage of spermiogenesis in $\mathrm{TAM}^{-/-}$ mice. CD36 is a regulator of the phagocytosis of apoptotic germ cells by Sertoli cells (Gillot et al. 2005). A significant down-regulation of $\mathrm{Cd} 36$ might contribute to the defective phagocytic ability of $\mathrm{TAM}^{-1-}$ Sertoli cells. We did not find the differential expression of other phagocytosis-related genes in $\mathrm{TAM}^{-/-}$testis based on the microarray data. $L d h c$, a key enzyme in glycolysis, was upregulated by 18 -fold in TAM ${ }^{-1-}$ Sertoli cells. We recently reported that lipids formed by Sertoli cells after engulfing apoptotic germ cells can be an energy source for Sertoli cells (Xiong et al. 2009). The impaired phagocytic ability of TAM $^{-1-}$ Sertoli cells might inhibit this metabolic pathway. The up-regulation of LDHC could be a compensatory response to the decreased lipid metabolism. Tnf was another potentially interesting upregulated gene in $\mathrm{TAM}^{-1-}$ Sertoli cells. It has been reported that TNF produced by Sertoli cells in rat testis with experimental autoimmune orchitis can triggers germ cell apoptosis (Suescun et al. 2003). The marked up-regulation of Tnf in $\mathrm{TAM}^{-1-}$ Sertoli cells might involve in the impaired spermatogenesis. The expression of TNF by Sertoli cells and its biological function in spermatogenesis in pathological condition has not been extensively studied, and should be worthwhile to investigate. Although TAM RTKs were completely inactivated in $\mathrm{TAM}^{-1-}$ Sertoli cells, the expression of their common ligand (Gas6) was significantly upregulated. This observation raised another interesting issue: the GAS6/TAM system may regulate its own gene expression to balance their biological function; we are investigating this possibility.

In conclusion, we analyzed in detail the phenotypes of male fertility and spermatogenesis duo to lacking TAM RTKs in mice, and demonstrated some mechanisms probably underlying the observed histological defects. The data provide novel insight into the roles of TAM RTKs in regulating spermatogenesis and male fertility.

\section{Materials and Methods}

\section{Animals}

Mice singly mutant for TAM RTKs were kindly provided by Dr Lemke (Salk Institute for Biological Studies, La Jolla), and were progeny of the original colony with a genetic background of $50 \% 129 / \mathrm{sv} \times 50 \% \mathrm{C} 57 \mathrm{BL} / 6$. Double and triple mutant mice were produced by cross mating of the single mutants. The wildtype control mice were the littermates of the mutant mice. The animals had free access to food and water, and were handled in compliance with the guideline for the care and use of laboratory animals established by the Chinese Council on Animal Care.

\section{Fertility assessment}

To assess male fertility, 8-week-old mutant males were mated with wild-type females at a ratio of $1: 1$ in cages. Three cages were set for each genotype. Total litter number was recorded for 6 months, and mean number of the three cages each genotype was presented in Results.

\section{Histological analysis}

Testes and epididymides were removed from mice and embedded in paraffin. After fixation in Bouin's solution, a serial of sections of $5 \mu \mathrm{m}$ in thickness were cut for appropriate staining after deparaffinization and dehydrations. The tubule diameter was measured under light microscope. Three mice each group were used for histological analysis. At least 150 seminiferous tubule sections from three animals were examined.

\section{Isolation of Sertoli, Leydig and spermatogenic cells}

The procedure for the isolation of Sertoli cells, LCs and spermatogenic cells was based on a previous description (Wang et al. 2006). Briefly, decapsulated testes were incubated with $0.5 \mathrm{mg} / \mathrm{ml}$ of collagenase (Sigma) at room temperature for 15 min with gentle oscillation, and then were filtered through $100 \mu \mathrm{m}$ copper meshes to collect interstitial cells and seminiferous tubules.

The interstitial cells were cultured in F12/DMEM medium (Gibco) containing 10\% FCS in an incubator containing 5\% $\mathrm{CO}_{2}$ at $32{ }^{\circ} \mathrm{C}$. After $24 \mathrm{~h}$, the interstitial cells were treated by $0.125 \%$ trypsin for $5 \mathrm{~min}$ to collect LCs. The LCs were counted and reseeded to examine the purity by staining for HSD3B1.

Seminiferous tubules were resuspended in the collagenase at room temperature for an additional $20 \mathrm{~min}$ to remove myoid cells. Then, the tubules were cut into small pieces and incubated with $0.5 \mathrm{mg} / \mathrm{ml}$ of hyaluronidase (Sigma) for $15 \mathrm{~min}$ with gentle oscillation and pipetting. The cell suspensions were cultured in F12/DMEM supplemented with $10 \%$ FCS at $32{ }^{\circ} \mathrm{C}$ for $24 \mathrm{~h}$. Non-adherent spermatogenic cells were collected, and those adhered to Sertoli cells were removed by a treatment with hypotonic solution (20 mM Tris, pH 7.4) for 1 min. Twentyfour hours later, Sertoli cells were recovered by treatment with $0.125 \%$ trypsin for $5 \mathrm{~min}$, and reseeded to evaluate the purity by staining for WT1 (a marker of Sertoli cells). 


\section{Immunostaining}

For immunohistochemistry, the testicular sections were incubated in PBS containing $3 \% \mathrm{H}_{2} \mathrm{O}_{2}$ for $15 \mathrm{~min}$ to block endogenous peroxidase activity, and then soaked in a citrate buffer and microwaved at $100{ }^{\circ} \mathrm{C}$ for $10 \mathrm{~min}$ for antigen retrieval. After blocking with $5 \%$ normal bovine serum, the sections were incubated overnight at $4{ }^{\circ} \mathrm{C}$ with the primary antibodies purchased from Santa Cruz Biotechnology (Santa Cruz, CA, USA), polyclonal antibodies against TYRO3 (SC1095), AXL (SC1096), MER (SC6873), WT1 (SC192), and PCNA (SC7907). After rinsing with PBS, the sections were incubated with the biotinylated secondary antibody, goat antirabbit IgG (Zhongshan, Beijing, China), at room temperature for $30 \mathrm{~min}$. The streptavidin-peroxidase activity was visualized with diaminobenzidine method. Negative controls were incubated with preimmune serum instead of primary antibodies. The sections were counterstained with hematoxylin and mounted with Canada balsam (Sigma) for observation.

For immunocytochemistry, Sertoli cells and LCs were cultured in Lab-Tek Chamber Slide (Nunc, Naperville, IL, USA; four chambers per slide), germ cells were spun onto slides. After washing twice with PBS, cells were fixed with cold methanol at $-20{ }^{\circ} \mathrm{C}$ for $1 \mathrm{~min}$. The endogenous peroxidase activity was blocked by a treatment with $3 \% \mathrm{H}_{2} \mathrm{O}_{2}$ in methanol for $15 \mathrm{~min}$. Then, cells were permeabilized by a 15 min treatment with $0.3 \%$ Triton X-100 in PBS. After preincubation with 5\% normal bovine serum in PBS at room temperature for $1 \mathrm{~h}$, the slides were incubated with the polyclonal antibodies against TYRO3, AXL, and MER at room temperature for $90 \mathrm{~min}$. The succeeding procedures were identical to the corresponding ones in immunohistochemistry staining.

\section{Western blotting}

Total cell lysates were prepared with cell lysis buffer (BioDevTech, Beijing, China). Protein concentration was measured using the micro-bicinchonic acid method (Pierce Biotechnology, Rockford, IL, USA). Equal amount of proteins were subject to SDS-PAGE, and electrotransferred onto PVDF membrane (Millipore, Bedford, MA, USA). After blocking with $5 \%$ nonfat dry milk in Tris-buffered saline (TBS) for $1 \mathrm{~h}$, the membranes were incubated with primary antibodies (Santa Cruz) at appropriate dilutions at $4{ }^{\circ} \mathrm{C}$ overnight: polyclonal antibodies against TYRO3, AXL, MER, WT1, VASA (SC97185), and HSD3B1 (SC30821). After washing twice with TBS, the membranes were incubated with appropriated peroxidaseconjugated affinipured secondary antibodies (Zhongshan) at room temperature for $1 \mathrm{~h}$. After washing twice with TBS, antigen-antibody complex was visualized using an enhanced chemiluminescence detection kit (Zhongshan).

\section{TUNEL assay}

Apoptotic cells were detected using TUNEL staining kit (Zhongshan) based on the manufacture's instructions. Briefly, after blocking endogenous peroxidase as description above, the testicular sections were incubated with terminal deoxynucleotidyl transferase labeling for overnight at $4{ }^{\circ} \mathrm{C}$. After washing with $\mathrm{PBS}$, the sections were incubated with antiFITC-HRP conjugate at $37^{\circ} \mathrm{C}$ for $2 \mathrm{~h}$, and then visualized with diaminobenzidine. The sections were counterstained with hematoxylin.

\section{Analysis of spermatozoa}

Epididymides were removed from 10-week-old mice, and cut to 1 -mm-long pieces in DMEM medium with $10 \%$ FCS. Then the small pieces were homogenized to dissociate somatic cells, then incubated at $32{ }^{\circ} \mathrm{C}$ for $10 \mathrm{~min}$ to allow dispersion of sperm. The sperm number was counted with a hemocytometer. The sperm motility was examined as previously described (Baker et al. 1996).

\section{Electron microscopy}

Epididymal sperm were pelleted by centrifugation for $5 \mathrm{~min}$ at $1000 \mathrm{~g}$, and fixed in $2.5 \%$ glutaraldehyde (Sigma) in PBS at $4{ }^{\circ} \mathrm{C}$ for $2 \mathrm{~h}$. After washing twice with PBS, the pellets were postfixed in $1 \%$ osmium tetroxide (Fisher Scientific Co., Fair Lawn, NJ, USA) for an additional $2 \mathrm{~h}$ at $4{ }^{\circ} \mathrm{C}$. After dehydrating with graded acetone, the pellets were embedded using an araldite embedding kit (Polysciences Inc., Warrington, PA,

Table 2 Primers used for real-time PCRs.

\begin{tabular}{lll}
\hline & & Primer pairs $\left(5^{\prime}-3^{\prime}\right)$ \\
\cline { 2 - 3 } Target genes & Forward & Reverse \\
\hline N-Cadherin & CACAGCCACAGCCGTCATC & GCAGTAAACTCTGGAGGATTGTCAT \\
Ldhc & TGG & GCCCTTAACCAGCGTGGTAA \\
$C d 36$ & CATCTTCTCAAAATTCGAGTGA & TGGGAGTAGACAAGGTACAACCC \\
Mer & GAAGGCGGTAGACCAGAC & GTAGGGGGATTCTCCTTGGA \\
$G a s 6$ & CGCCAAGGCCGCATT & TCGGTCCGCCAGGCT \\
Ar & CGAGTCTTCTCACACTGCTGTT & GCACTCTTGATATCGTGGATAGA \\
Amp & TGGCGGTCCTTCACTAATGTC & TTGAAAACCAAGTCAGGTGCAA \\
$28 \mathrm{~s}$ rRNA & AGCCAGCCGGACATGTTG & TGGTGAGGAGGCAATTGGTT \\
\hline
\end{tabular}

$L d h c$, lactate dehydrogenase C; Tnf, tumor necrosis factor- $\alpha$; Abp, androgen binding protein; $A r$, androgen receptor; Amh, anti-Müllerian hormone; 28s rRNA, 28s ribosome RNA. 
USA). Ultrathin sections (70 $\mathrm{nm}$ in thickness) were cut and placed on formvar-coated copper grids, stained with uranyl acetate and lead citrate, and viewed with a Jem 1200 Ex transmission electron microscope (JEOL, Tokyo, Japan).

\section{ORO staining}

To examine lipid droplets in testis, frozen sections $(8 \mu \mathrm{m}$ in thickness) were cut and mounted on poly-L-lysine coated slides. The sections were fixed with $10 \%$ neutral-buffered formalin for $15 \mathrm{~min}$. After a wash with $70 \%$ ethanol for $1 \mathrm{~min}$, the sections were incubated with ORO solution (ORO saturated solution in isopropanol:water $=3: 2$, Sigma) for $15 \mathrm{~min}$. The sections were washed with $70 \%$ alcohol for $10 \mathrm{~s}$ to remove background staining, then were counterstained with Harris' hematoxylin and mounted in glycerol: PBS at 9:1 (v/v). Lipid droplets were visualized and counted under a microscope (IX71, Olympus).

\section{Staining for HSD3B1}

Staining for HSD3B1 was carried out based on a method described by Klinefelter et al. (1987). Briefly, LCs were fixed with $10 \%$ formalin in PBS and dried for $10 \mathrm{~min}$ at room temperature. Then the cells were stained with a mix of solution A $(1 \mathrm{mg}$ NBT dissolved in $0.6 \mathrm{ml}$ of $1 \mathrm{mg} / \mathrm{ml}$ etiocholan-3 $\beta$-ol17 -one in DMSO) and solution $\mathrm{B}\left(10 \mathrm{mg} \beta-\mathrm{NAD}^{+}\right.$in $9.5 \mathrm{ml}$ PBS) for $90 \mathrm{~min}$. After rinsing in distilled water, the slides were mounted with glycerol:PBS $=1: 1(\mathrm{v} / \mathrm{v})$.

\section{Measurement of testosterone}

Blood samples were collected by bleeding from tail of 15 -week-old mice, and sera were collected by centrifugation at $1500 \mathrm{~g}$ for $10 \mathrm{~min}$. The testosterone level in serum was measured by RIA as previously described (Suescun et al. 1985). Five animals from each group were examined and data were presented as mean \pm S.E.M.

\section{Microarray analysis}

Microarray analysis was performed according to the protocol of Affymetrix's instructions. Briefly, total RNA was extracted from the testes of 3-week-old WT and TAM ${ }^{-1-}$ mice using Trizol reagent (Invitrogen), and reversely transcribed into the first strand cDNA with superscript II reverse transcriptase using a T7-Oligo(dT) promoter primer. Following RNase H-mediated second-strand cDNA synthesis, the double-stranded cDNA was purified and served as a template in the subsequent in vitro transcription reaction, which was carried out in the presence of T7 RNA polymerase and a biotinylated nucleotide analog for cRNA amplification and biotin labeling. The biotinylated cRNA targets were cleaned up with an RNeasy mini column (Qiagen), fragmented to 50-200 nucleotides, and hybridized to GeneChip Mouse Genome 430/2.0 (Affymetrix). After staining with Fluidics Station 450, the microarrays were scanned with a GeneChip Scanner 3000, and the signals were analyzed with GeneChip Operating Software (GCOS 1.4). The data from duplicates on the arrays were fused. Changes of more than twofold in intensities were considered differentially expressed genes, which were listed in Supplementary Table 1 and classified using Onto-Express according to their gene ontology categories.

\section{Quantitative RT-PCR}

Sertoli cells were isolated from the testes of 3-week-old mice, total RNAs were extracted from the cells using Trizol reagent according to the manufacturer's instructions. The RNA $(1 \mu \mathrm{g})$ was reversely transcribed into cDNA in $20 \mu \mathrm{l}$ of RT reaction mixture containing $2.5 \mu \mathrm{M}$ random hexamers, $2 \mathrm{mM}$ dNTPs and $200 \mathrm{U}$ M-MLV reverse transcriptase (Promega). Real-time PCR was performed with Power SYBR Green PCR master mix kit (Applied Biosystems, Foster City, CA, USA) using an $\mathrm{ABI}$ PRISM 7300 real-time cycle (Applied Biosystems). The mRNA levels of target genes were normalized to $28 \mathrm{~s}$ rRNA. The primers for real-time PCR were listed in Table 2.

\section{Statistical analysis}

For all comparisons, statistical analysis was carried out by Student's $t$-test to generate $P$ values. Statistical significance was defined as $P<0.05$. The calculations were performed with SPSS version 11.0 statistic software.

\section{Declaration of interest}

The authors declare that there is no conflict of interest that could be perceived as prejudicing the impartiality of the research reported.

\section{Funding}

This work was supported by Special Funds for Major State Basic Research Project of China (grant no. 2007CB947504, 2006CB504001).

\section{Acknowledgements}

We sincerely thank Dr Greg Lemke for providing TAM RTK mutant mice.

\section{References}

Baccetti B, Fraioli F, Paolucci D, Selmi G, Spera G \& Renieri T 1979 High prolactin level and double spermatozoa. Gamete Research 2 193-199.

Baker J, Hardy MP, Zhou J, Bondy C, Lupu F, Bellve AR \& Efstratiadis A 1996 Effects of an Igf1 gene null mutation on mouse reproduction. Molecular Endocrinology 10 903-918.

Caraux A, Lu Q, Fernandez N, Riou S, Di Santo JP, Raulet DH, Lemke G \& Roth C 2006 Natural killer cell differentiation driven by Tyro3 receptor tyrosine kinases. Nature Immunology 7 747-754.

Cheng CY \& Mruk DD 2002 Cell junction dynamics in the testis: Sertoli-germ cell interactions and male contraceptive development. Physiological Reviews 82 825-874.

Dunkel L, Hirvonen V \& Erkkila K 1997 Clinical aspects of male germ cell apoptosis during testis development and spermatogenesis. Cell Death and Differentiation 4 171-179.

Ezeh UI 2000 Beyond the clinical classification of azoospermia: opinion. Human Reproduction 15 2356-2359. 
Firestein R, Nagy PL, Daly M, Huie P, Conti M \& Cleary ML 2002 Male infertility, impaired spermatogenesis, and azoospermia in mice deficient for the pseudophosphatase Sbf1. Journal of Clinical Investigation 109 1165-1172.

Gillot I, Jehl-Pietri C, Gounon P, Luquet S, Rassoulzadegan M, Grimaldi P \& Vidal F 2005 Germ cells and fatty acids induce translocation of CD36 scavenger receptor to the plasma membrane of Sertoli cells. Journal of Cell Science 118 3027-3035.

Hafizi S \& Dahlback B 2006a Gas6 and protein S. FEBS Journal 273 5231-5244.

Hafizi S \& Dahlback B $2006 b$ Signalling and functional diversity within the Axl subfamily of receptor tyrosine kinases. Cytokine \& Growth Factor Reviews 17 295-304.

Kastner P, Mark M, Leid M, Gansmuller A, Chin W, Grondona JM, Decimo D, Krezel W, Dierich A \& Chambon P 1996 Abnormal spermatogenesis in RXR beta mutant mice. Genes and Development 10 80-92.

Kerr JB \& de Kretser DM 1974 Proceedings: the role of the Sertoli cell in phagocytosis of the residual bodies of spermatids. Journal of Reproduction and Fertility 36 439-440.

Klinefelter GR, Hall PF \& Ewing LL 1987 Effect of luteinizing hormone deprivation in situ on steroidogenesis of rat Leydig cells purified by a multistep procedure. Biology of Reproduction 36 769-783.

Lemke G \& Lu Q 2003 Macrophage regulation by Tyro 3 family receptors. Current Opinion in Immunology 15 31-36.

Lemke G \& Rothlin CV 2008 Immunobiology of the TAM receptors. Nature Reviews. Immunology 8 327-336.

Lewis-Jones I, Aziz N, Seshadri S, Douglas A \& Howard P 2003 Sperm chromosomal abnormalities are linked to sperm morphologic deformities. Fertility and Sterility $79212-215$.

Lu Q \& Lemke G 2001 Homeostatic regulation of the immune system by receptor tyrosine kinases of the Tyro 3 family. Science 293 306-311.

Lu Q, Gore M, Zhang Q, Camenisch T, Boast S, Casagranda F, Lai C, Skinner MK, Klein R, Matsushima GK et al. 1999 Tyro-3 family receptors are essential regulators of mammalian spermatogenesis. Nature 398 723-728.

Maeda Y, Shiratsuchi A, Namiki M \& Nakanishi Y 2002 Inhibition of sperm production in mice by annexin $\mathrm{V}$ microinjected into seminiferous tubules: possible etiology of phagocytic clearance of apoptotic spermatogenic cells and male infertility. Cell Death and Differentiation 9 742-749.

Manning G, Whyte DB, Martinez R, Hunter T \& Sudarsanam S 2002 The protein kinase complement of the human genome. Science 298 1912-1934.

Matzuk MM \& Lamb DJ 2002 Genetic dissection of mammalian fertility pathways. Nature Cell Biology 4 s41-s49.

Mruk DD \& Cheng CY 2004 Sertoli-Sertoli and Sertoli-germ cell interactions and their significance in germ cell movement in the seminiferous epithelium during spermatogenesis. Endocrine Reviews 25 747-806.

Mueller SRT, Takai Y, Bronson RA \& Wimmer E 2003 Loss of nectin-2 at Sertoli-spermatid junctions leads to male infertility and correlates with severe spermatozoan head and midpiece malformation, impaired binding to the zona pellucida, and oocyte penetration. Biology of Reproduction 69 1330-1340.

Nakamura T, Yao R, Ogawa T, Suzuki T, Ito C, Tsunekawa N, Inoue K, Ajima R, Miyasaka T, Yoshida Y et al. 2004 Oligo-astheno-teratozoospermia in mice lacking Cnot7, a regulator of retinoid $X$ receptor beta. Nature Genetics 36 528-533.
Nakanishi Y \& Shiratsuchi A 2004 Phagocytic removal of apoptotic spermatogenic cells by Sertoli cells: mechanisms and consequences. Biological \& Pharmaceutical Bulletin 27 13-16.

Newton SC, Blaschuk OW \& Millette CF 1993 N-cadherin mediates Sertoli cell-spermatogenic cell adhesion. Developmental Dynamics 197 $1-13$.

Ogawa T, Ito C, Nakamura T, Tamura Y, Yamamoto T, Noda T, Kubota Y \& Toshimori K 2004 Abnormal sperm morphology caused by defects in Sertoli cells of Cnot7 knockout mice. Archives of Histology and Cytology 67 307-314.

Robinson DR, Wu YM \& Lin SF 2000 The protein tyrosine kinase family of the human genome. Oncogene 19 5548-5557.

Russell LD, Warren J, Debeljuk L, Richardson LL, Mahar PL, Waymire KG, Amy SP, Ross AJ \& MacGregor GR 2001 Spermatogenesis in Bclwdeficient mice. Biology of Reproduction 65 318-332.

Suescun MO, Gonzalez SI, Chiauzzi VA \& Calandra RS 1985 Effects of induced hypoprolactinemia on testicular function during gonadal maturation in the rat. Journal of Andrology 6 77-82.

Suescun MO, Rival C, Theas MS, Calandra RS \& Lustig L 2003 Involvement of tumor necrosis factor-alpha in the pathogenesis of autoimmune orchitis in rats. Biology of Reproduction 68 2114-2121.

Tang H, Chen S, Wang H, Wu H, Lu Q \& Han D 2009 TAM receptors and the regulation of erythropoiesis in mice. Haematologica 94 326-334.

Wang H, Wang H, Xiong W, Chen Y, Ma Q, Ma J, Ge Y \& Han D 2006 Evaluation on the phagocytosis of apoptotic spermatogenic cells by Sertoli cells in vitro through detecting lipid droplet formation by Oil Red O staining. Reproduction 132 485-492.

Wang $H$, Chen S, Chen Y, Wang $H$, Wu H, Tang H, Xiong W, Ma J, Ge Y, Lu Q et al. 2007 The role of Tyro 3 subfamily receptors in the regulation of hemostasis and megakaryocytopoiesis. Haematologica 92 643-650.

van der Weyden L, Arends MJ, Chausiaux OE, Ellis PJ, Lange UC, Surani MA, Affara N, Murakami Y, Adams DJ \& Bradley A 2006 Loss of TSLC1 causes male infertility due to a defect at the spermatid stage of spermatogenesis. Molecular and Cellular Biology 26 3595-3609.

Xiong W, Chen Y, Wang H, Wang H, Wu H, Lu Q \& Han D 2008 Gas6 and the Tyro 3 receptor tyrosine kinase subfamily regulate the phagocytic function of Sertoli cells. Reproduction 135 77-87.

Xiong W, Wang H, Wu H, Chen Y \& Han D 2009 Apoptotic spermatogenic cells can be energy sources for Sertoli cells. Reproduction 137 469-479.

Yamada D, Yoshida M, Williams YN, Fukami T, Kikuchi S, Masuda M, Maruyama T, Ohta T, Nakae D, Maekawa A et al. 2006 Disruption of spermatogenic cell adhesion and male infertility in mice lacking TSLC1/IGSF4, an immunoglobulin superfamily cell adhesion molecule. Molecular and Cellular Biology 26 3610-3624.

Yefimova MG, Sow A, Fontaine I, Guilleminot V, Martinat N, Crepieux P, Canepa S, Maurel MC, Fouchecourt S, Reiter E et al. 2008 Dimeric transferrin inhibits phagocytosis of residual bodies by testicular rat Sertoli cells. Biology of Reproduction 78 697-704.

Received 16 March 2009

First decision 15 April 2009

Revised manuscript received 8 July 2009

Accepted 13 July 2009 